\title{
Constitucionalización del Derecho Laboral en Colombia: reconocimiento de derechos laborales a las personas que ejercen la prostitución
}

\section{Constitutionalization of the Labor Law in Colombia: Acknowledgment of the labor right to prostituted persons}

Recibido: 11/07/2012 Aprobado: 03/11/2012

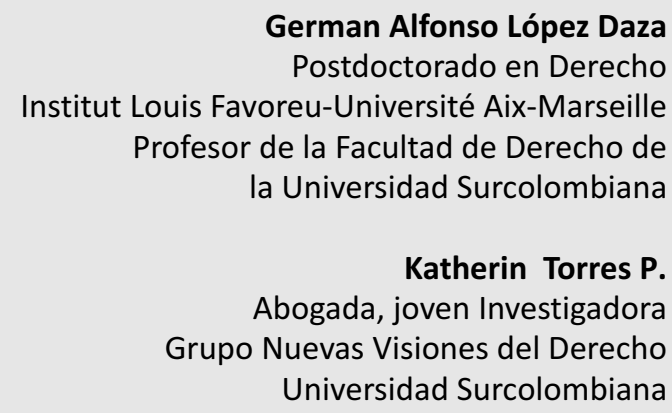

German Alfonso López Daza

Postdoctorado en Derecho Profesor de la Facultad de Derecho de

la Universidad Surcolombiana

Abogada, joven Investigadora

Universidad Surcolombiana

germanlo@usco.edu.co

katherintorresp@gmail.com

\section{RESUMEN}

El presente artículo, pretende estudiar el fenómeno de la constitucionalización del derecho laboral, a partir de la Sentencia T- 629 de 2010, en donde se reconocen derechos laborales a las trabajadoras sexuales, pues como se podrá evidenciar, este fallo constituye un cambio en la visión del derecho, en donde retoma las subreglas creadas por la Corte Constitucional más importantes en el derecho laboral.

\section{PALABRAS CLAVE}

Constitucionalismo, Neoconstitucionalismo, Constitucionalización, Derecho Laboral, Trabajadoras Sexuales.

\section{ABSTRACT}

This article aims to study the phenomenon of constitutionalization of labour law from the Judgment T-629 of 2010 , where are recognized labor rights to sex workers, because as will be evident, this ruling is a change in the vision of the right, where takes the subrules, most important of the Constitutional Court in the labour law

\section{KEYWORDS}

Constitutionalism, Neoconstitutionalism, constitucionalization Labor Law, Sex workers. 


\section{INTRODUCCIÓN}

Es indudable la connotación que han tenido los Tribunales Constitucionales, creados después de la segunda guerra mundial, pues ellos se han encargado de dinamizar y actualizar el derecho, a través del análisis ius-fundamental de los casos sometidos a su estudio, lo que ha generado que el derecho se examine desde una óptica en donde principios como el de dignidad humana, libertad e igualdad irradian toda la actividad estatal.

En Colombia, la expedición de la Constitución de 1991, trajo consigo la creación de la Corte Constitucional, quien inició funciones a partir de 17 de febrero de 1992, desde entonces, ha sido evidente la labor de enseñanza de la supremacía constitucional, los principios y valores fundantes de nuestro Estado Social de Derecho. Su labor ha sido tan ardua y activa, que sus precedentes constituyen un referente obligado para la actividad judicial.

Lo anterior, ha generado que todas las áreas del derecho se vean permeadas por la aplicación directa de los derechos fundamentales, los principios consagrados en la Constitución y además se atiendan las interpretaciones que ha realizado la Corte Constitucional en los distintos temas.

Esta cualidad ha sido denominada como la constitucionalización del derecho, en donde el centro de gravedad del orden jurídico se desplaza. Desde el siglo XIX, ese orden tuvo a la ley como eje esencial. A partir de fines del siglo XX, el eje es la Carta Fundamental. Hoy debe, en consecuencia, hablarse de principio de constitucionalidad, porque la Constitución no es ya más un Derecho de preámbulo ni otro de índole política, sino que es verdadero Derecho. (Favoreu, 1998)

Este trabajo pretende analizar la constitucionalización en el ámbito del derecho laboral en
Colombia, para ello, en una primera parte se establecerán las características del proceso de constitucionalización en un ordenamiento jurídico, aspecto crucial para el desarrollo de este escrito; en un segundo momento, se analizarán conceptos como el constitucionalismo y el neoconstitucionalismo, con el fin de distinguirlos del término constitucionalización, y finalmente, se analizará la sentencia T- 629 de 2010 en donde se estudia el caso de una persona que ejerce la prostitución, quien solicita el reconocimiento de los derechos laborales, fallo que ha sido relevante en la interpretación del derecho laboral, lo anterior, para determinar si a partir de la Constitución de 1991, se podría hablar de una nueva categoría de derecho laboral constitucionalizado.

\section{1. ¿QUÉ SE DEBE ENTENDER POR CONSTITUCIONALIZACIÓN DEL DERECHO?}

El término constitucionalización se utiliza por primera vez, en la reunión constitutiva de la Asociación Francesa de Constitucionalistas, en la Facultad de Derecho de la Universidad Saint - Maur en 1980, apoyado en los estudios realizados por el profesor Luis Favoreu', que se publicaron en ese mismo año.

El profesor Favoreu (1998), afirma que en el proceso de Constitucionalización deben tenerse en cuenta: la acumulación de normas constitucionales, que se caracteriza porque las disposiciones constitucionales son directamente aplicables a los individuos y son impulsadas por el desarrollo de la jurisprudencia de los Tribunales Constitucionales, a través del control de constitucionalidad de las leyes. Aunado a lo anterior, en dicho proceso, juega un papel importante la difusión de las normas constitucionales, es decir, la irrigación de la Constitución, pues esta es considerada como "regla de derecho", lo que traduce a que las normas constitucionales no necesitan ser desarrolladas por ninguna ley para que sean aplicadas y se manifiesta en el hecho que las

1.- Los estudios del profesor L. Faverou son: “L'apport du Conseil constitutionnel au droit public", Pouvoirs, 1980, № 13; y el texto: "L'influence de la jurisprudence du Conseil constitutionnel sur les diverses branches du droit", documentos que fueron redactados en 1979. 
interpretaciones de las normas realizadas por los Tribunales Constitucionales, son aplicadas por los jueces ordinarios.

Sobre este concepto Peters, Aznar y Gutiérrez (2010), afirman que:

La constitucionalización implica que una constitución (o un derecho constitucional) puede aparecer en un proceso a lo largo del tiempo. Implica igualmente que un texto jurídico (o varios textos jurídicos) pueden adquirir (o, eventualmente, perder) propiedades constitucionales en un proceso positivo de realimentación. Por lo tanto, un texto puede parecerse más (o menos) a una constitución. Puede ser, resumidamente, una constitución en construcción (p. 212).

En el mismo sentido, el profesor Guastini (2009), afirma que la constitucionalización del ordenamiento jurídico es un proceso de transformación en donde éste resulta "totalmente impregnado por las normas constitucionales". Como característica de este proceso, se cuenta con una constitución "invasora", "entrometida" que condiciona tanto la legislación como la jurisprudencia, así como la acción de los políticos y las relaciones sociales. Indicando además, que un ordenamiento jurídico puede estar más o menos constitucionalizado, dependiendo de las condiciones de constitucionalización que se estén cumpliendo en dicho ordenamiento, lo que le permite afirmar, que la constitucionalización es una cuestión de grado y no un concepto bipolar que no admite punto intermedio. Contrario sensu, cuando un ordenamiento no está constitucionalizado, la Constitución se circunscribe solamente a ser un "catálogo" de normas que limitan el actuar del Estado.

Para dicho autor, son necesarias dos condiciones para predicar la existencia del fenómeno de la constitucionalización:

a) Rigidez de la Constitución: La Constitución está por encima de las leyes ordinarias y no puede ser modificada o derogada, salvo con un procedimiento especial y más complejo que el proceso de creación de las leyes. Llama la atención el autor, en el hecho de que el proceso de constitucionalización es mucho más pronunciado, cuando existen una serie de principios constitucionales que son inmutables e inmodificables.

b) Garantía Jurisdiccional de la Constitución: Consiste esencialmente, en el control de constitucionalidad que se hace a la Ley. De esta manera, dependiendo del sistema o modelo, se tiene que este puede ejercerse de manera difusa y con efectos inter-partes (como ocurre en Estados Unidos), o bien, puede realizarse el control de manera concentrada, por un Tribunal Constitucional con efectos erga - omnes (como sucede enAlemanía, España y Colombia).

Existen otras condiciones, que aunque no son requisitos sine qua non, no dejan de ser menos importantes en el análisis del proceso de constitucionalización:

i. La fuerza vinculante de la Constitución, es decir, que el texto constitucional en su integridad es considerado como norma jurídica genuina que produce efectos jurídicos;

ii. La sobreinterpretación constitucional, apoyada fundamentalmente en la actividad de los Tribunales Constitucionales, que realizan una interpretación extensiva del texto constitucional, de donde se extraen normas tácitas, en otras palabras, "no existe discrecionalidad legislativa", nada es ajeno al juez constitucional;

iii. La aplicación directa de las normas constitucionales, que genera que las normas de la Constitución sean aplicadas a todas las relaciones sociales (entre particulares, 0 entre estos y el Estado), bien sea porque existe un vacío en la Ley, o bien porque existiendo norma aplicable que solucione el caso, esta es a todas luces injusta, visión distinta a la concepción liberal clásica de la función de la Constitución, que afirmaba que ésta solo regula las relaciones entre ciudadano y Estado. 
iv. La interpretación conforme de la Ley, se traduce al hecho de que al existir dos interpretaciones de una norma para aplicar al caso concreto, el operador judicial, debe escoger aquella que sea coherente con la Constitución, conservando de esta manera la validez de la Ley, armonizándola con los postulados constitucionales.

v. La influencia de la Constitución en las relaciones políticas, condición que no es fácil de precisar para el autor, pues ello depende de distintos elementos, tales como: el contenido de la Constitución, la existencia o no de Tribunales Constitucionales y la postura de los jueces y los actores políticos, afirmando en este último aspecto que "las normas constitucionales son más o menos usadas en la argumentación política (de los órganos y de los actores) para justificar sus acciones".

En el mismo sentido, algunos autores nacionales, al estudiar el fenómeno de la constitucionalización, coinciden en algunas de las características 0 condiciones descritas previamente, tal como el profesor Mantilla (2007), quien afirma que el término "constitucionalizar" se utiliza para nombrar distintas técnicas de aplicación de las normas constitucionales en las relaciones entre particulares, contando entre las más representativas: el control de constitucionalidad, la interpretación conforme, incluyendo una técnica, cual es la acción de tutela, pues en el caso colombiano, ha sido evidente la influencia de estos fallos en las decisiones de los jueces ordinarios.

Lo anterior, nos permite concluir que el término constitucionalización es un concepto que genera un replanteamiento en la manera tradicional de interpretar la Ley, pues se deja de lado la exégesis de la norma, para darle paso a una interpretación armónica y coherente con los principios constitucionales, una interpretación que es dinámica, gracias a la labor de los Tribunales Constitucionales, quienes cambian "el derecho", según las realidades sociales. Este concepto, permite afirmar que se ha ampliado el espectro de actuación y aplicación de la Constitución, pues esta se encuentra regulando todos los ámbitos sociales tanto privados como públicos de las personas.

Ahora bien, partiendo de estas características, se procederá a realizar algunas precisiones de los términos "constitucionalismo" y "neoconstitucionalismo", conceptos que en ocasiones suele confundirse con la constitucionalización.

\section{2. ¿QUÉ SE ENTIENDE POR "CONSTITUCIO- NALISMO" Y "NEOCONSTITUCIONALISMO"?}

El constitucionalismo, es un movimiento que surgió en los siglos XVII y XVIII, en el marco de la Revolución Francesa y Américana, tuvo como bases fundamentales la división de poderes y la defensa de los derechos del hombre; su finalidad radicó en doblegar el gobierno de los hombres por el de las leyes, para lograr lo anterior, establecieron en las Constituciones el sistema de frenos y contrapesos (checks and balances).

Al respecto, el profesor Luis Carlos Sáchica (1999), indica que:

El constitucionalismo es el esfuerzo por racionalizar el ejercicio del poder político, sometiéndolo a la ley. Pretensión que equivale a transformar la fuerza, la coerción, en una facultad regulada por normas jurídicas. 0 , con más precisión: llegar a un punto en que quienes gobiernan solo pueden actuar cuando la ley los autoriza, de la manera, con los efectos y para los fines en ella previstos, dado el supuesto de que también los gobernados únicamente pueden obrar dentro de la ley.

2.- Además de los conceptos "constitucionalismo" y "neoconstitucionalismo", existen otros términos que son descritos por el profesor Gomes Canotilho, tales como "nuevo constitucionalismo", "constitucionalismo societario", "transconstitucionalismo" y "constitucionalismo multinivel", que no se desarrollan en este trabajo, por razones de extensión del mismo. Sin embargo, se puede consultar en el artículo de dicho autor, denominado "Principios y Nuevos Constitucionalismos: El problema de los nuevos principios". En RedCe. Año 7. Núm 14. Julio-diciembre/2010. 
De esta manera, el autor indica que este periodo del constitucionalismo culminó con "constituciones políticas escritas y codificadas (...) y la figura que lo resume: El Estado de derecho liberal".

En lo que refiere al neoconstitucionalismo, el profesor Gomes Canotilho (2010), afirma que este concepto se adhiere a una concepción de Constitución "juridificadora" de la política, haciendo énfasis en esquemas metodológicos de interpretación y aplicación que optimicen las normas. De igual manera, los principios se perfilan como "vehículos" de una estatalidad abierta "sea en el sentido de su importancia para la constitucionalización del orden jurídico, sea en el sentido de instrumentos de integración de constelaciones de políticas nacionales".

En ese orden de ideas, siguiendo al profesor Luigi Ferrajoli (2007) el Estado Constitucional de Derecho sería el nuevo modelo en formación, situado históricamente a partir de la Segunda Guerra Mundial, con ejemplos emblemáticos como la Constitución de Italia (1947), Alemania (1949) y España (1978), en donde surgen las constituciones rígidas y el control de la constitucionalidad de la leyes ordinarias, con un triple cambio en el paradigma: a) en la naturaleza y estructura del derecho, b) en la naturaleza de la ciencia jurídica y $\quad$ c) en la jurisdicción.

En este punto, el profesor Raymundo Gil (2011), es claro al indicar que:

La Constitución se presenta como el centro, base y fundamento de todo el sistema jurídico, pero es una Constitución pensada en términos de principios y directrices que se interpretan no bajo el vetusto esquema de los métodos tradicionales del derecho (subsunción), sino mediante la ponderación.

Lo anterior, permite afirmar lo siguiente: los conceptos de constitucionalización y neoconstitucionalismo, están íntimamente relacionados, pues el primero, es un cambio estructural en tanto que el segundo es un cambio doctrinal. Tal como lo enseña Comanducci (2012) "uno favorece y sustenta al otro, en un proceso de acción y retroacción".

\section{CONSTITUCIONALIZACIÓN DEL DERECHO LABORAL}

De conformidad con las características de constitucionalización descritas anteriormente, al analizarlas en nuestro ordenamiento jurídico, se puede afirmar que en Colombia, existe una acumulación de normas constitucionales, por la labor del control de constitucionalidad, función consagrada en el artículo 241 de la Constitución Política, a través de esta actividad, se han suprimido normas que han sido contrarias a la Carta Política y de igual manera se han declarado exequibles de manera condicional algunas de ellas, en este último aspecto, la Corte Constitucional ha establecido los parámetros de interpretación que sean acordes a los postulados constitucionales.

De igual manera, se encuentra la característica descrita por el profesor Favoreu: la irrigación de normas constitucionales, pues la misma Corte Constitucional ha sido enfática en determinar que las normas constitucionales no necesitan ningún desarrollo legal para que sean efectivas. Como ejemplo emblemático, tenemos el derecho a la salud, que a pesar de encontrarse consagrado como un derecho de segunda generación 0 derecho prestacional, la jurisprudencia de la Corte Constitucional ha realizado una interpretación extensiva, a través de figuras como la conexidad, incluso en la actualidad, se considera el derecho a la salud, como un derecho fundamental autónomo, tal como se estableció en sentencia T-706 de 2008. ${ }^{3}$

A lo anterior, podemos agregar lo siguiente: A partir de la expedición de la Constitución de 1991, la puesta en marcha del mecanismo de protección de los derechos fundamentales: la acción de tutela, ha tenido un gran impacto e influencia en las decisiones de los jueces ordinarios y en los parámetros para fijar

3.- Como jurisprudencia reciente del derecho a la salud como fundamental, se puede citar la sentencia T- 792 de 2012, T-940 de 2012 , y la T- 003 de 2013 
las políticas públicas, muy a pesar de que los efectos de las sentencias de tutela son inter-partes.

Con el fin determinar el grado de constitucionalización en el derecho laboral, se ha optado por analizar en detalle el caso que resolvió la Corte Constitucional en sentencia T- 629 de 2010, con ponencia realizada por el Magistrado Juan Carlos Henao, en donde se reconocen derechos laborales a las trabajadoras sexuales, tanto por la relevancia del asunto en el mundo jurídico, como por los diversos temas que allí se desarrollan y que en últimas, recogen las subreglas jurisprudenciales de esta corporación en el ámbito laboral.

\section{EL RECONOCIMIENTO DE DERECHOS LABORALES A LAS TRABAJADORAS SEXUALES: REINTERPRETACIÓN DEL DERECHO LABORAL}

Para dimensionar el alcance del fallo de la Corte Constitucional, es importante tener en cuenta que las personas que han ejercido la prostitución han sido históricamente menospreciadas y rechazadas, por desarrollar una actividad que atenta contra la moral y las buenas costumbres.

Es así, como el Derecho se ha encargado de abordar esta actividad, desde tres perspectivas o modelos: El Prohibicionista, que pretende suprimir, y proscribir todas las conductas relacionadas con la explotación económica del sexo, en donde el "cliente" se considera como una víctima de la actividad desarrollada por la persona prostituida. El Modelo Abolicionista, que busca que estas actividades no tengan ningún tipo de reconocimiento por parte del mundo jurídico, desconociendo el fenómeno; así, "lo que se elimina no es el hecho en sí de la prostitución, sino la aceptación de su existencia y por tanto de regulación normativa"
Y finalmente, el modelo Reglamentista que a diferencia de los otros, reconoce el fenómeno de la prostitución, por lo cual, procede a regular esta actividad con el fin de que no perturbe la convivencia de la comunidad, estableciendo para ello territorios especiales para el desarrollo de la prostitución, y en donde se adoptan medidas de higiene y seguridad, no para la persona prostituida, sino para la protección del cliente a quien se le debe garantizar un servicio en condiciones de calidad.

En el ordenamiento jurídico colombiano existe un régimen mixto de los modelos mencionados anteriormente, pues por una parte está la tendencia a prohibir la explotación sexual, como se evidencian en los delitos tipificados en el Código Penal y su capítulo dedicado a los Delitos contra la libertad, integridad y formación sexuales en el que se contemplan diversos delitos como la "Inducción a la prostitución", el "proxenetismo con menor de edad", el "constreñimiento a la prostitución", la "prostitución de menores", el "turismo sexual", la "utilización o facilitación de medios de comunicación para ofrecer actividades sexuales con menores de edad" incluyendo, el delito de "omisión del deber de denuncia", estableciendo circunstancias de agravación punitiva relacionadas con la edad de la víctima o la relación que se tenía con esta ${ }^{6}$; y por otra parte, se encuentra la tendencia de reglamentar esta actividad, desde una perspectiva urbanística en donde se regula el uso del suelo para el desarrollo de la actividad de la prostitución ${ }^{7}$, cabe mencionar de igual manera el Decreto 1355 de 1970, modificado por el Decreto 520 de 1971, Código Nacional de Policía, en donde se determina que el sólo ejercicio de la prostitución no es punible, y en donde se impone la obligación al Estado de tener institutos para la rehabilitación de quienes ejercen la prostitución de maneragratuita.

4.- Estos modelos son desarrollados por la Corte Constitucional en Sentencia C-629 de 2010, en el acápite 2.4.1 del fallo, siguiendo el trabajo de Rey, Mata y Serrano (2004)

5.- Sentencia C- 629 de 2010. M.P. Juan Carlos Henao

6.-Dichos tipos penales, se encuentran determinados los artículos 213 y subsiguientes del Código Penal, Ley 599 de 2000, modificado por la Ley 1236 de 2008, Ley 1329 y 1336 de 2009.

7.- Al respecto, se puede consultar la Ley 902 de 2004 y su Decreto Reglamentario 4002 de 2004 
Ahora bien, en la sentencia objeto de análisis, la Corte entra a resolver la tutela que interpuso una ciudadana contra un bar por la presunta vulneración de los derechos laborales, estabilidad laboral reforzada, mínimo vital, seguridad social, debido proceso y demás; por cuanto según la accionante, "laboró" desde febrero de 2008, anunciándole a su empleador en el mes de diciembre de dicha anualidad que se encontraba en estado de embarazo, y que a pesar de ello, continuó trabajando normalmente hasta el mes de enero de 2009, fecha en la cual el empleador le dio la orden de "administrar el negocio"; sin embargo, esta relación continuó hasta el mes de marzo de 2009, momento en el cual el empleador le comunicó la decisión de no dejarla trabajar más por el estado de embarazo (que era de alto riesgo) por cuanto se había contratado a otra persona para que ejecutara la labor que ella desarrolló.

De esta manera, la actora solicitó la protección de los derechos descritos anteriormente, y el reintegro laboral en las mismas condiciones y cargo, con el pago de salarios y prestaciones sociales dejadas de percibir.

En los fallos de primera y segunda instancia, se denegó la tutela de los derechos invocados; sin embargo, se concedieron algunas medidas alternativas tales como oficiar al Ministerio de Trabajo para que realice labores de inspección y vigilancia sobre dichos establecimientos y se le preste la asesoría jurídica y la atención médica necesaria a la actora con el apoyo del Instituto Colombiano de Bienestar Familiar (ICBF).

Como se puede ver, no es un caso fácil, pues lo primero que se pensaría es que no es jurídicamente posible predicar la existencia de un contrato que recaiga en la prestación de servicios sexuales, por lo prescrito en los artículos 1502 y 1518 del Código Civil, ya que el objeto de dicho negocio jurídico, sería "ilícito", en la medida que atenta contra la moral y las buenas costumbres. Sin embargo, si se admitiera la posibilidad de existencia y validez de este tipo de contratos, se encontraría otra dificultad: ¿Cómo separar esa delgada línea entre lo que sería una actividad "legal y lícita" y la eventual tipificación de los delitos descritos previamente?

Pues bien, la Corte resolvió estas dificultades, realizando un análisis de la naturaleza jurídica del concepto de igualdad, así como la aplicación de los juicios como forma de neutralizar la discriminación; por cuanto "esta compleja figura constitucional, debe servir de parámetro para el estudio de la prostitución como actividad y para determinar si de su ejercicio se pueden derivar determinadas relaciones reconocidas por el Derecho, de las que se desprenden derechos amparables y dentro de ellos los laborales fundamentales que la actora reclama en el presente proceso".

Luego, desde la óptica del Derecho Comparado estudia el tratamiento que se le ha dado a la prostitución, en donde en algunos países como Holanda y Alemania, se establece una normativa en la cual el "empresario" debe concertar un acuerdo laboral que garantice las condiciones del servicio en términos sanitarios, incluyendo derechos y garantías para quienes desarrollan esta actividad.

Sin embargo, el tratamiento de la prostitución por parte del Derecho Internacional tiene por objeto la supresión y persecución del fenómeno, en cuanto se halla vinculado con delitos como la trata de personas - la explotación de seres humanos para alcanzar cuantiosos beneficios económicos. ${ }^{9}$ Fundamentán-

8.- Consideración No. 23 de la Sentencia C- 629 de 2010

9.-Existen una serie de instrumentos de la Asamblea General de las Naciones Unidas, que rechazan la prostitución, tales como: El Convenio para la Represión de la Trata de Personas y de la Explotación de la Prostitución Ajena, de 1949, La Convención sobre Eliminación de Todas las Formas de Discriminación contra las Mujeres, adoptada mediante Resolución No. /180, de 1979. En 2000, se suscribe el Protocolo Para Prevenir, Reprimir y Sancionar la Trata de Personas, Especialmente Mujeres y Niños, que complementa la Convención de las Naciones Unidas Contra la Delincuencia Organizada Transnacional, la Convención de las Naciones Unidas contra la Delincuencia Organizada Transnacional (Convención de Palermo) y su Protocolo para Prevenir, Reprimir y sancionar la Trata de Personas, especialmente en Mujeres y Niños. 
dose en los Convenio No. 29 de 1930 sobre trabajo forzoso ${ }^{10}$, Convenio No. 102 de 1952 relativo a la norma mínima de la seguridad social y el Convenio No. 182 de la OIT, sobre la eliminación de las peores formas de trabajo infantil ${ }^{11}$, así como las recomendaciones No. 35 y 136 en donde se referencia el trabajo forzoso relacionado con la trata de personas.

El anterior estudio, permitió a la Corte efectuar las siguientes conclusiones: “i) Se reprime con sanción penal desde la mera inducción a la prostitución de otro, con fines de lucro económico u otro beneficio; ii) lo anterior, por cuanto la prostitución suele estar relacionada con la trata de personas humanas con fines de explotación; bajo ese contexto o de cualquier otra forma de crimen organizado, la prostitución debe reprimirse; iii) no obstante, corresponde a los Estados la protección sanitaria, humanitaria y asistencial de la persona sexualmente explotada; iv) no es, por otra parte, punible ni perseguible el "sólo ejercicio de la prostitución", v) ni lo es la existencia y el funcionamiento de establecimientos de comercio en los que se ejerce la prostitución". ${ }^{12}$

No obstante, a pesar de que para la Corte es claro que el ejercicio de la prostitución no constituye per-se un delito, siempre y cuando sea una actividad voluntaria y libre, aún tenía que resolver el asunto desde el ámbito contractual, toda vez que se encontraba con el argumento de que el objeto y la causa del contrato sería ilícito, pues al tenor de la interpretación jurídica, el mismo recaería en una actividad prohibida por la Ley, que atenta contra la moral y las buenas costumbres.

Pues bien, apoyándose en anteriores pronunciamientos $^{13}$ la Corte reitera que al no existir un consenso en la sociedad sobre lo que es "moral", no se puede concebir el concepto de las buenas costumbres como "figura paralela que pueda competir con él", por lo tanto, "la idea de "buenas costumbres" no ha de partir de un modelo ideal de comportamiento, sino de un "mínimo de corrección exigido" por las "'representaciones colectivas"', que a su vez provienen de las reglas legales y su interpretación, de los usos y prácticas sociales de común y abierta aceptación y también de sus rápidos cambios" $^{\text {"14 }}$

Lo anterior, permite afirmar que la licitud de un contrato o de una prestación, será el resultado:

a. De la autonomía de la voluntad de los sujetos contratantes, que se manifiesta en la existencia de la libertad para contratar ${ }^{15}$, que pretenden la consecución no sólo del interés particular, sino del bienestar común, y que además, se comprometen a cumplir con las obligaciones y prestaciones que se deriven de las normas que regulan la actividad.

b. De la forma en que operen los bienes constitucionales que respaldan el ejercicio de la autonomía de la voluntad.

En ese orden de ideas, y aunado al hecho que la prostitución es una opción sexual válida dentro de nuestro Estado Social de Derecho ${ }^{16}$, esta constituye en sí misma una actividad económica, sometida a las reglas del mercado (oferta y demanda); sin embargo, se aclara que esta actividad será válida siempre y cuando se respete la libertad y la dignidad humana de quienes presten el servicio, además de las normas urbanísticas sobre el uso del suelo, la salubridad y demás existentes.

Lo anterior implica que el desarrollo de la prostitución, permite obtener recursos económicos a

10.-Aprobado por Colombia, mediante Ley No. 23 de 1967.

11.-Aprobado por Colombia, mediante Ley No. 704 de 2001.

12.-Considerando No. 67 de la Sentencia T-629 de 2010

13.- Entre ellos, en la Sentencia C- 350 de 2009, Sentencia T- 301 de 2004 y la Sentencia T- 391 de 2003,

14.- Considerando No. 89 de la Sentencia T- 629 de 2010

15.- Es decir, no hay constreñimiento o coacción, también se refleja en el hecho en que no existe un abuso de la posición dominante en la relación jurídico contractual o prácticas restrictivas de la competencia.

16.- Esta afirmación, se encuentra en la Sentencia C- 507 de 1999. 
quienes realizan dicha actividad, lo que quiere decir que se garantizarían los derechos a la subsistencia y al mínimo vital, ${ }^{17}$ que representa también una fuente legítima de trabajo, siempre y cuando se cumplan las exigencias legales.

Una vez establecido que la prostitución es una actividad económica, válida en términos contractuales, cabe consultar si eventualmente podría configurarse la existencia del elemento de la subordinación o dependencia entre la persona prostituida y los establecimientos de comercio, indispensable para predicar la existencia de un contrato de trabajo. ${ }^{18}$

Se suele considerar que ningún contrato, incluyendo el laboral, puede suponer para una de las partes afrentas a su libertad y dignidad humanas. De tal suerte, "el subordinar la voluntad de alguien para que tenga tratos sexuales con un tercero, aparece contrario de modo radical con tales valores. De allí la repulsa que generalmente suscite formular el asunto". 19

Sin embargo, teniendo en cuenta el carácter proteccionista del Derecho laboral, y con el fin de evitar interpretaciones contrarias a los principios constitucionales que fundamentan el Estado Social del Derecho y que generarían una discriminación negativa a quienes se dedican a la prostitución, la Corte entiende que si puede existir un contrato laboral "cuando él o la trabajadora sexual ha actuado bajo plena capacidad y voluntad, cuando no hay inducción ninguna a la prostitución, cuando las prestaciones sexuales y demás del servicio, se desarrollen bajo condiciones de dignidad y libertad para el trabajador y por supuesto cuando exista subordinación limitada por el carácter de la prestación, continuidad y pago de una remuneración previamente definida. ${ }^{20}$

Una conclusión del juez constitucional que no pretende ni auspiciar la actividad, ni desconocer su carácter no ejemplificante, mas sí proteger a quienes se ganan la vida y cumplen con su derecho deber al trabajo a través de la prostitución ejercida no de modo independiente sino al servicio de un establecimiento de comercio dedicado a ello. ${ }^{21}$

A pesar de lo anterior, al admitirse la posibilidad de la existencia de un contrato laboral de esta naturaleza la Corte plantea los siguientes interrogantes: "¿Cuáles son los límites del reconocimiento que precede? ¿Hasta dónde llegan las consecuencias jurídicas vinculantes de afirmar que pueden existir y se pueden asegurar las prestaciones debidas de los contratos de trabajo que se celebren entre trabajadores sexuales y establecimientos de comercio donde se ofrecen tales servicios? ¿Cómo saber si con ello no sólo se están reconociendo derechos al trabajador sexual, sino también a quien lo emplea, manifestaciones de la subordinación y del cumplimiento de instrucciones específicas, despido con y sin justa causa?"22, inquietudes que no son respondidas, pues para la Corte, es el legislador quien en el ejercicio de sus competencias debe brindar respuesta, aún así, la corporación estableció unos parámetros mínimos que se deben tener en cuenta al momento de regular esta actividad:

17.-Artículos 25 y 26 de la Constitución Política.

18.-Al respecto, el artículo 23 del Código Sustantivo de Trabajo determina la concurrencia de los siguientes requisitos para que exista un contrato de trabajo: i) Actividad Personal, ii) Remuneración o contraprestación de la actividad que se desarrolla, y la iii) Subordinación o dependencia, entendida como la facultad que tiene el empleador de impartir órdenes, instrucciones y el cumplimiento reglamentos, lo que permite dirigir la actividad del trabajador.

19.- Considerando No. 143 de la Sentencia T- 629 de 2010

20.- E incluso, habrá derecho al pago de salarios y prestaciones legales por el tiempo que haya durado el servicio, aun cuando la actividad dentro de la cual se ha ejercido la prostitución pueda ser considerada ilícita, conforme lo establecido en el art. 43 C.S.T. Considerando No. 108 de la Sentencia T-629 de 2010.

21.-Vid. Pablo de Lora. “¿Hacernos los suecos? La prostitución y los límites del Estado”. En Doxa, Cuadernos de Filosofía del Derecho, 30 (2007), pp. 451-470.

22.-Considerando No. 153 de la Sentencia T-629 de 2010. 
i. Los límites constitucionales de la libertad, la dignidad humana, la igualdad, la no discriminación y de respeto al Estado de Derecho;

ii. Los principios y reglas generales del Derecho laboral existente;

iii. El deber de crear y reconocer las muchas especificidades y diferencias que una relación laboral para la prestación de servicios sexuales por cuenta ajena amerita, dada la cercanía que el objeto del trabajo tiene con ámbitos de la intimidad y de la integridad moral y física;

iv. El deber de considerar al trabajador 0 trabajadora sexual como sujeto de especial protección, por ser la parte débil del contrato y sobre todo por las condiciones propias del trabajo y la discriminación histórica y actual de la que suele ser víctima por la actividad que ejerce;

v. El deber de aplicar la "imaginación jurídica" para que con los límites, prohibiciones, garantías y derechos que se establezcan, se cree la diferencia que haga que la persona que trabaja con el sexo pueda estar en condiciones para elegir en libertad e igualdad su proyecto de vida.

A pesar de que precariamente se reconoce la existencia de la subordinación o dependencia en este caso específico, también es cierto que se reconoce de manera frágil el derecho a ser reintegrado al puesto de trabajo en el caso de despido injusto, lo anterior, teniendo en cuenta que al limitar las garantías de derechos para quienes desarrollan esta actividad, no se promovería el ejercicio de este oficio, que a pesar de todo, no resulta loable, ni recomendable.

Después de este análisis, la Corte entra a determinar la procedencia de la acción de tutela, en lo que refiere a la legitimación por activa y por pasiva, encontrando los presupuestos procesales para entrar a resolver de fondo el caso.
Llama la atención el hecho que la actora, básicamente solicita que se declare la existencia de un contrato de trabajo entre ella y el bar en donde desarrollaba su actividad, con el pago de las acreencias laborales que derivan de dicha actividad. Es claro, que para obtener este tipo de reconocimientos se tiene que iniciar el proceso ordinario laboral ante el juez correspondiente, en donde se prueben los requisitos de existencia del contrato de trabajo.

Sin embargo, la Corte retoma el desarrollo jurisprudencial que ha sentado en los casos de despido de mujeres embarazadas o en período de lactancia o como madres cabeza de familia, en donde afirma que a pesar de la existencia de mecanismos ordinarios de defensa, la acción de tutela es procedente por ser ellas sujetos de especial protección, a la luz de los artículos 13, 43 y 53 de la Constitución.

Para dicha corporación: "Esta interpretación reconoce otra manifestación de la garantía constitucional para proteger a la madre trabajadora, al estimar procedente la tutela como vía judicial para hacer efectivos derechos laborales, pues para ellas como regentes del hogar, la privación de los mismos hasta las resultas del proceso ordinario, hacen a este mecanismo no idóneo ni eficaz. Estas mismas circunstancias hacen igualmente que se pueda configurar un perjuicio irremediable, pues la situación del despido coloca a la mujer en cuestión y a sus hijos ante la amenaza inequívoca de quedar privados de su derecho al mínimo vital" ${ }^{24}$

Esto ha generado que se abra una puerta que permite excepcionalmente que en sede de tutela, se declare la existencia de un contrato realidad ${ }^{25}$, como en el caso que se analiza, pues para la Corte: Una dimensión de raigambre constitucional, que a su vez determina las razones por las cuales es el juez de tutela, antes que el ordinario, el llamado a asumir la competencia para conocer del caso y para proveer, si

23.-Considerando No. 154 Íbidem.

24.-Considerando No. $171 \mathrm{lbidem}$

25.- Tal como lo decidió la Corte en las sentencias T- 528 de 2008, T- 292 de 2011, T- 954 de 2011 y T-287 de 2011 
las pruebas lo permiten, la protección judicial privilegiada del amparo constitucional que toda trabajadora, madre cabeza de familia, lactante 0 gestante posee, cuando su empleador incumple de manera injustificada y con grave afectación para sus condiciones de vida y de los suyos, las obligaciones laborales que conforme al Derecho le corresponden.

Esta postura extralimita las competencias que se han otorgado legalmente a esta acción, claramente la Corte asume las facultades que son otorgados a los jueces ordinarios laborales para este tipo de conflictos y entra a resolverlos, so pretexto de la protección o garantía de derechos fundamentales. Advirtiéndose además, que en sede de tutela no se reunirían todos los presupuestos probatorios adecuados y pertinentes para conllevar a la afirmación de la existencia 0 no de un contrato realidad, aunado al hecho que la parte demandada no contaría con la oportunidad para ejercer adecuadamente su derecho de defensa, en el entendido que la contestación de la tutela se realiza en un término de 48 horas.

Ahora bien, en tratándose de los derechos que se vulnerarían a la mujer despedida que se encuentra en estado de gestación y que además es cabeza de familia, (mínimo vital), generarían un perjuicio irremediable que para la Corte debe ser abordado vía tutela, aclarando que para la prosperidad de las pretensiones de esta acción, deben acreditarse los siguientes hechos:

I. Que el despido haya tenido lugar durante el embarazo 0 dentro de los 3 meses siguientes al parto.

II. Que a la fecha del despido, el empleador haya conocido o haya debido conocer la existencia del estado de embarazo, pues la trabajadora notificó su estado oportunamente.

III. Que el motivo del despido haya sido el estado de embarazo.
IV. Que no exista permiso del inspector del trabajo si se trata de trabajadora oficial o privada.

V. Que el despido afecte el mínimo vital de la actora y/o del que está por nacer. ${ }^{26}$

Para acreditar la existencia de los requisitos del contrato de trabajo en el caso concreto, la Corte se sustenta en la presunción establecida en el artículo 24 del Código Sustantivo de Trabajo, que determina que "Se presume que toda relación de trabajo personal está regida por un contrato de trabajo", así como en la presunción prescrita en el artículo 210 del Código de Procedimiento Civil, que reza: se hará presumir ciertos los hechos susceptibles de prueba de confesión sobre los cuales versen las preguntas asertivas admisibles, contenidas en el interrogatorio escrito, (...) respecto de los hechos de la demanda y de las excepciones de mérito, 0 de sus contestaciones, cuando no habiendo interrogatorio el citado no comparezca".

Además teniendo en cuenta las declaraciones rendidas por los testigos en el caso expuesto, la Corte llega a la conclusión de que efectivamente la actora prestó los servicios sexuales y de "acompañamiento" bajo dos modalidades: la del trabajo independiente y la del trabajo dependiente. A pesar de que la corporación encontró acreditado los tres elementos del contrato de trabajo, no hubo certeza sobre el tiempo en que esta relación tuvo inicio y concluye:

"Se configuró un contrato realidad cuyos términos en el tiempo no están determinados con total precisión en el proceso de tutela, salvo en lo que hace a la fecha de despido, pero cuya existencia se acredita de manera suficiente para reconocer la violación de derechos fundamentales al trabajo, la seguridad social, la igualdad, la dignidad, la protección de la mujer en estado de embarazo, el derecho del que está pornacer, el fuero materno y el mínimo vital".

26.- Sobre estos requisitos, se pueden consultar las sentencias T-373 de 1998, T-426 de 1998, T-874 de 1999; requisitos aplicados en las sentencias T-002, T-014, T-053, T-063, T-070, T-381, T-619 y T-1040 de 2006; T-056, T-069, T-071, T-195, T-221, T-465, T-546, T$561, \mathrm{~T}-761$ de 2007 y T-513 de 2008, entre otras. 
Por lo anterior, la Corte emite las siguientes órdenes:

- Como forma de reparar los derechos fundamentales conculcados y de proteger su derecho a la igualdad, la indemnización equivalente a los salarios de sesenta (60) días de que trata el artículo 239, num $3^{\circ}$ del Código Sustantivo de Trabajo.

- El pago de las doce (12) semanas de descanso remunerado de que trata 236 del C.S.T. (modificado por el artículo 34 de la Ley 50 de 1990) que, como en el caso anterior, correrán por cuenta del empleador en la medida en que el mismo no vinculó a la actora a la seguridad social, como correspondía en razón de su contrato de trabajo.

- Ante la ausencia de una clara definición del salario convenido, la estimación pecuniaria de las ordenes anteriores se calculará teniendo como base el salario mínimo legal vigente al momento del despido de la actora (art. 132 num $1^{\circ}$ C.S.T., modificado por el art. 18 de la ley 50 de 1990)

- Por la falta de certidumbre sobre las fechas exactas en que tuvo ocurrencia la relación laboral de la actora con el establecimiento de comercio y también ante la presunta solución de continuidad que se habría podido presentar en esta relación durante algún tiempo, también en aplicación del principio de igualdad formal, no puede el juez constitucional reconocer otros derechos, prestaciones e indemnizaciones reclamados por la actora, y a las que podría haber lugar de acuerdo con el contrato de trabajo.

- En consecuencia, deberá la actora si a bien lo tiene y dentro del término de caducidad de la acción laboral ordinaria, dar inicio al proceso ante el juez del trabajo competente, para que en él se soliciten y recauden las pruebas necesarias y pertinentes con las cuales se establezca el monto de los derechos laborales aún no protegidos.

- Por último, no atiende a la solicitud de reintegro. Porque conforme lo dicho en las consideraciones generales, por la especificidad de la prestación ordinaria que ejecutó la actora y por la forma como ésta actividad puede reñir con los ideales liberales, racionales y de la dignidad humana del constitucionalismo y en particular con los deberes dispuestos desde el Derecho internacional para los Estados, estima la Sala que tal prestación debe estar excluida de las garantías laborales de quien trabaja por cuenta ajena como prostituta 0 prostituto.

Este caso constituye un ejemplo claro de la constitucionalización del derecho laboral, pues es evidente el giro interpretativo que ha realizado la Corte en el tema de derechos laborales para las personas que ejercen la prostitución, con el fin de garantizar y proteger los derechos que se alegaban vulnerados, en especial por una persona sujeta de especial protección, como lo son las madres cabeza de familia.

Fíjese que la Corte ordena que si a bien lo tiene la actora, puede iniciar el proceso ordinario laboral, no para solicitar la declaración de la existencia de un contrato laboral, sino para que en él se soliciten y recauden las pruebas necesarias y pertinentes con los cuales se establezcan el monto de los derechos laborales no protegidos, es decir, que se demuestre la fecha de inicio y terminación de la duración del contrato laboral, así como los ingresos que obtuvo la actora, con el fin de cuantificar las condenas, pues en sede de tutela, la Corte, asumiendo competencias que no tiene, declara la existencia de la relación laboral.

Este asunto compone uno de los muchos ejemplos en los cuales la Corte asume las facultades que tiene el juez ordinario laboral, pues declaraciones de esta naturaleza son propias de un proceso ordinario laboral, por lo que al emitir el juez de tutela ordenes con carácter definitivo sobre la base de la existencia de tal figura, desborda sus competencias, pues para ello nuestra legislación ha prescrito un trámite y unas etapas que no deben ser desconocidas en el fallo de tutela, máxime si se tiene en cuenta que es el mismo juez constitucional quien declaró la existencia del contrato laboral que se sustituye. ${ }^{27}$ 
Sin duda alguna, el fallo implica un cambio en la concepción que se tenía, pues es claro, que antes de él era impensable predicar la existencia de un contrato cuyo objeto es la prestación de servicios sexuales.

\section{REFERENCIAS BIBLIOGRÁFICAS}

- Avendaño, G. (2010) La constitucionalización de los principios laborales. Ediciones Doctrina y Ley.

- Bernal, C. (2007) El neoconstitucionalismo a debate. Editorial Universidad Externado de Colombia.

- Bernal, C. (2009) El neoconstitucionalismo y la normatividad del Derecho. Editorial Universidad Externado de Colombia.

- Carbonell M. (2007) Teoría del neoconstitucionalismo. Ensayos escogidos. Madrid. Editorial Trotta - UNAM.

- Carbonell, M. (2008). Tendencias del constitucionalismo en Iberoamerica. UNAM.

- CIJUS. (2002) "Jurisprudencia Constitucional sobre el Derecho al Mínimo Vital. Estudios de caso: Despido injusto de mujer embarazada". Bogotá. Ediciones Uniandes

- Comanducci, P. (2012) Constitucionalización y Neoconstitucionalismo.

- http://umet.edu.ec/blogs/blog-derecho/wpcontent/uploads/2012/02/NEOCONSTITUCION ALISMO3.pdf

- Corral, H. (2004). Algunas reflexiones sobre la constitucionalización del derecho privado. Revista Derecho Mayor.

- De Lora, P. (2007) “¿Hacernos los suecos? La prostitución y los límites del Estado". En Doxa, Cuadernos de Filosofía del Derecho.

- Favoreu, L. (1998) La Constitucionalización del
Derecho. http://mingaonline.uach.cl/pdf/revider/ v12n1/art03.pdf

- Gil, R. (2011) El Neoconstitucionalismo y los Derechos Fundamentales. Biblioteca Jurídica Virtual del Instituto de Investigaciones Jurídicas de la UNAM. México.

- Gómez, J. (2010) Principios y Nuevos Constitucionalismos: El problema de los nuevos principios.

- Guastini, R. (2009). La Constitucionalización del ordenamiento jurídico: el caso italiano. Madrid. Editorial Trotta-UNAM.

- Mantilla, F. (2007) La Constitucionalización del Derecho Privado. Constitucionalización del Derecho Privado. Bogotá.

- Peters, A.; Aznar M. y Gutiérrez I. (2010) La Constitucionalización de la Comunidad Internacional. Valencia. Editorial Cedri.

- Rey, Mata y Serrano. Prostitución y Derecho. Madrid. ThomsonAranzadi. 2004, pp. 13-37.

- Sáchica, L. (1999). Derecho Constitucional General. Bogotá. Editorial Temis.

- Sánchez, G. (2008). La formulación constitucional del derecho al trabajo. Editorial Universidad Santiago de Cali.

\section{PÁGINAS WEB}

- Favoreu, Louis Joseph. (1998). "La Constitucionalización del Derecho". Disponible en: http://mingaonline.uach.cl/pdf/revider/v12n1/ art03.pdf. Consultado Mayo 2012.

- Paolo Comanducci (2012). "Constitucionalización y Neoconstitucionalismo" Disponible en: http://umet.edu.ec/blogs/blog-derecho/wpcontent/uploads/2012/02/NEOCONSTITUCION ALISMO3.pdfConsultado Abril 2012. 